\title{
Improving L-serine formation by Escherichia coli by reduced uptake of produced L-serine
}

\author{
Chenyang Wang ${ }^{1,2}$, Junjun $\mathrm{Wu}^{3}$, Binchao Shi ${ }^{1,4}$, Jiping Shi ${ }^{1,25^{*}}$ and Zhijun Zhao ${ }^{1,2^{*}}$
}

\begin{abstract}
Background: Microbial de novo production of L-serine, which is widely used in a range of cosmetic and pharmaceutical products, has attracted increasing attention due to its environmentally friendly characteristics. Previous pioneering work mainly focused on L-serine anabolism; however, in this study, it was found that L-serine could be reimported through the L-serine uptake system, thus hampering L-serine production.

Result: To address this challenge, engineering via deletion of four genes, namely, sdaC, cycA, sstT and tdcC, which have been reported to be involved in L-serine uptake in Escherichia coli, was first carried out in the L-serine producer $E$. coli ES. Additionally, the effects of these genes on L-serine uptake activity and L-serine production were investigated. The data revealed an abnormal phenomenon regarding serine uptake activity. The serine uptake activity of the $\triangle s d a C$ mutant was $0.798 \mathrm{nmol} \mathrm{min}^{-1}$ (mg dry weight) ${ }^{-1}$ after $30 \mathrm{~min}$, decreasing by $23.34 \%$ compared to that of the control strain. However, the serine uptake activity of the single sstT, cycA and tdcC mutants increased by $34.29 \%, 78.29 \%$ and $48.03 \%$, respectively, compared to that of the control strain. This finding may be the result of the increased level of sdaC expression in these mutants. In addition, multigene-deletion strains were constructed based on an sdaC knockout mutant. The $\Delta s d a C \Delta s s t T \Delta t d c C$ mutant strain exhibited $0.253 \mathrm{nmol} \mathrm{min}{ }^{-1}$ (mg dry weight) ${ }^{-1}$ L-serine uptake activity and the highest production titer of $445 \mathrm{mg} / \mathrm{L}$ in shake flask fermentation, which was more than three-fold the $129 \mathrm{mg} / \mathrm{L}$ production observed for the parent. Furthermore, the $\Delta s d a C \Delta s s t T \Delta t d c C$ mutant accumulated $34.8 \mathrm{~g} / \mathrm{L}$ L-serine with a yield of $32 \%$ from glucose in a 5 -L fermenter after $36 \mathrm{~h}$.
\end{abstract}

Conclusion: The results indicated that reuptake of $\mathrm{L}$-serine impairs its production and that an engineered cell with reduced uptake can address this problem and improve the production of L-serine in E. coli.

Keywords: L-serine, Uptake system, Gene knockout, Fermentation of L-serine

\section{Background}

L-Serine is a vital component of metabolism and an important material used in the pharmaceutical and cosmetic industries, with a $5-7 \%$ annual growth rate in its market demand currently $[1,2]$. The direct fermentation of cheaper carbon sources to obtain L-serine has become a promising production method because this method is environmentally friendly and allows easy extraction [3].

*Correspondence: shijp@sari.ac.cn; zhaozj@sari.ac.cn

${ }^{1}$ Biorefinery Laboratory, Shanghai Advanced Research Institute, Chinese Academy of Sciences, 99 Haike Road, Shanghai 201210, China

Full list of author information is available at the end of the article
Numerous exciting studies have demonstrated the successful microbial production of L-serine. For example, Peters-Wendisch al. [4] constructed a Corynebacterium glutamicum strain by examining key genes; overexpressing $\operatorname{ser}^{f r}$ (fr, feedback inhibition resistance), serB, and $\operatorname{ser} C$; and deleting $s d a A$. Subsequently, production of $36 \mathrm{~g} / \mathrm{L} \mathrm{L}$-serine was achieved by controlling SHMT activity with a folate supply in a 60-h fed-batch fermentation process [5]. Zhu et al. [6] also obtained a C. glutamicum strain engineered to minimize the byproducts L-alanine and L-valine by deleting alaT, avtA and $i l v N$ and achieved L-serine production of $42.6 \mathrm{~g} / \mathrm{L}$ in a $96-\mathrm{h}$ fedbatch fermentation process. In addition, Escherichia coli 
has been widely engineered for L-serine production due to its easy genetic manipulation and short growth period [7-9] (Fig. 1). For instance, E. coli DH5a was engineered to enhance $\mathrm{L}$-serine precursor production and strengthen the L-serine synthesis pathway by overexpressing $\operatorname{ser} A^{f r}$, $\operatorname{ser} B$ and $\operatorname{ser} C$. The recombinant strain produced $8.34 \mathrm{~g} / \mathrm{L}$ L-serine from glucose [10]. In 2016, Mundhada et al. [11] developed a strain of $E$. coli MG1655 lacking the L-serine degradation genes, $s d a A, s d a B$ and $t d c G$, and the L-serine hydroxymethyltransferase gene $g l y A$ and overexpressing the L-serine synthesis genes $\operatorname{ser} A^{f r}$, ser $B$ and $\operatorname{ser} C$ and the cysteine/homoserine transporter eamA, which led to $\mathrm{L}$-serine production of $11.7 \mathrm{~g} / \mathrm{L}$. Furthermore, the strain was modified for improved L-serine tolerance by adaptive laboratory evolution, and the L-serine production increased to $37 \mathrm{~g} / \mathrm{L}$ after $52 \mathrm{~h}$ of fermentation [12].

Notably, the previous study mainly focused on enhancing L-serine biosynthesis and decreasing the degradation of this compound. However, external L-serine could be reimported into cells and used for protein synthesis and to increase cell viability. This phenomenon may inhibit L-serine production during fermentation. Blocking reuptake by modifying the uptake process has been proven to be an efficient method. For instance, deletion of the $\mathrm{L}$-tryptophan uptake gene $m t r$ resulted in a decrease in
L-tryptophan uptake by $48 \%$ in E. coli [13], deletion of the L-threonine uptake gene sst $T$ reduced L-threonine uptake activity by $50 \%$ in $E$. coli [14], and mutation of the aminobutyric acid (GABA) uptake gene $\mathrm{GabP}_{\mathrm{Cg}}$ caused the strain to lose the ability to take up any GABA [15]. However, thus far, no study has investigated the effects of the L-serine uptake system on L-serine production and growth in E. coli.

Previously, four genes, namely, sst $T, c y c A, s d a C$ and $t d c C$, were reported to be related to $\mathrm{L}$-serine uptake in E. coli [16-23]. In the present study, first, the occurrence of L-serine reuptake was clearly demonstrated, and the functions of these four genes were verified by overexpression of these genes in the L-serine-producing strain ES. Furthermore, the four genes were knocked out in combination in ES. Single-gene deletion mutants and multigene deletion mutants were generated, and their growth, L-serine uptake activity and L-serine production were evaluated.

\section{Results}

Investigating whether L-serine could be reimported by $E$. coli

To determine whether L-serine was reimported, E. coli ES was inoculated into Luria-Bertani (LB) medium with

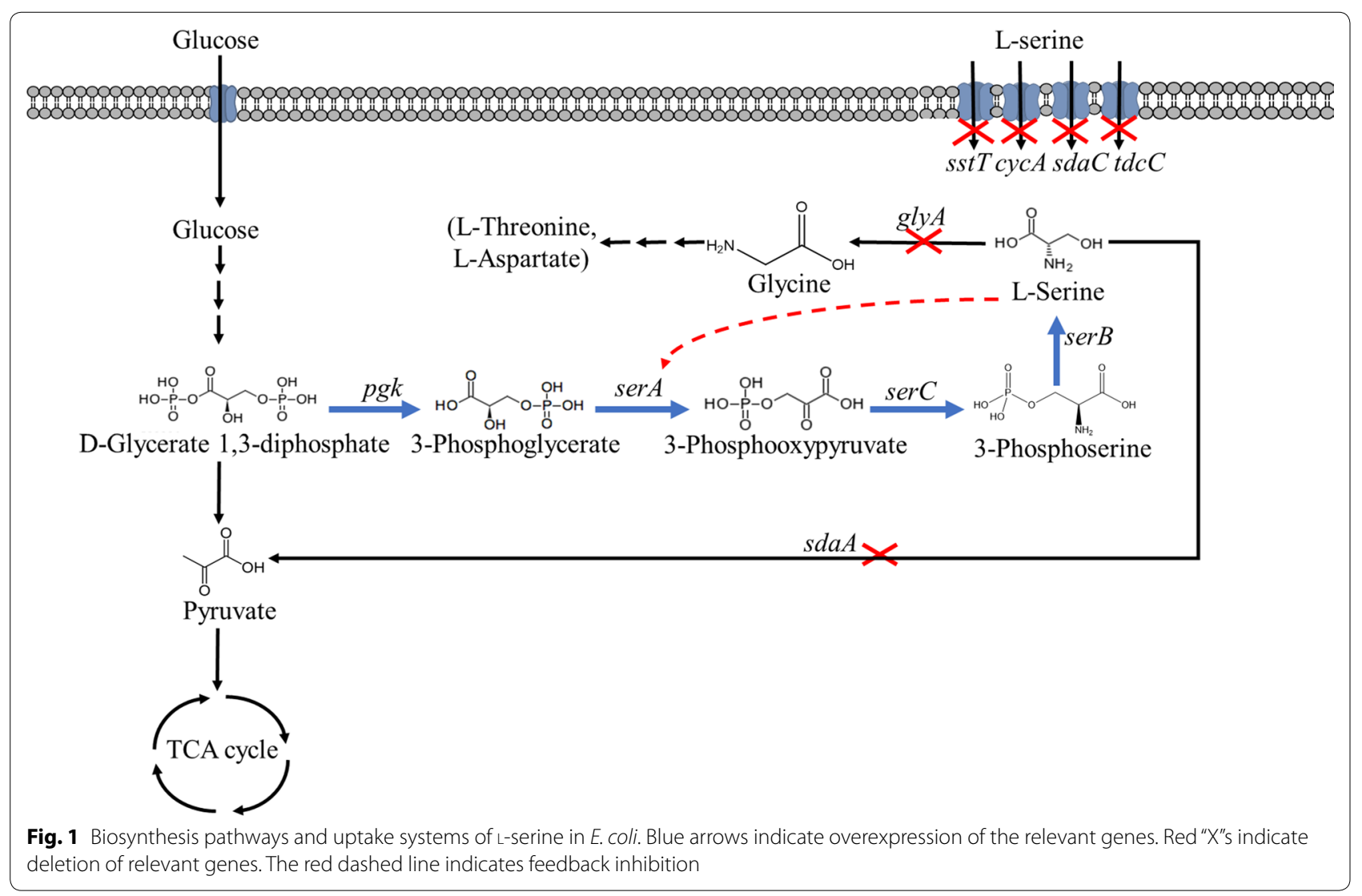


an additional $2 \mathrm{~g} / \mathrm{L}$ or $4 \mathrm{~g} / \mathrm{L} \mathrm{L}$-serine. An HPLC chromatogram of the L-serine standard solution is shown in Additional file 1: Fig. S1. As shown in Fig. 2, the L-serine concentration decreased to $1.05 \mathrm{~g} / \mathrm{L}$ and $1.17 \mathrm{~g} / \mathrm{L}$ at $4 \mathrm{~h}$. Then, the $\mathrm{L}$-serine concentrations were further reduced to less than $0.15 \mathrm{~g} / \mathrm{L}$ at $6 \mathrm{~h}$. It was observed that the maximum specific growth rates of the strains with an additional $2 \mathrm{~g} / \mathrm{L}$ and $4 \mathrm{~g} / \mathrm{L} \mathrm{L}$-serine were $1.47 \mathrm{~h}^{-1}$ and $1.65 \mathrm{~h}^{-1}$, respectively, which were 1.12 - and 1.26 -fold that of the corresponding control strain, respectively. The final optical densities at $600 \mathrm{~nm}\left(\mathrm{OD}_{600}\right)$ of the strains in $\mathrm{LB}$ medium with an additional $2 \mathrm{~g} / \mathrm{L}$ and $4 \mathrm{~g} / \mathrm{L} \mathrm{L}$-serine increased by $56 \%$ and $67 \%$, respectively, compared to that of the control $\left(\mathrm{OD}_{600} \sim 5.3\right)$. This demonstrated that L-serine could be imported and metabolized and provided easily assimilable carbon and nitrogen sources for cell growth. This raises the question of how the uptake takes place and whether it has any effect on L-serine accumulation.

\section{Relevance of transporters for L-serine uptake}

The four genes $s d a C, c y c A$, sst $T$ and $t d c C$, which were reported to be related to L-serine uptake, were overexpressed in E. coli ES [16-23]. The L-serine uptake activity of these strains was evaluated. As shown in Fig. 3, the L-serine uptake activity (30 $\mathrm{min})$ of ES/pSC-12, ES/

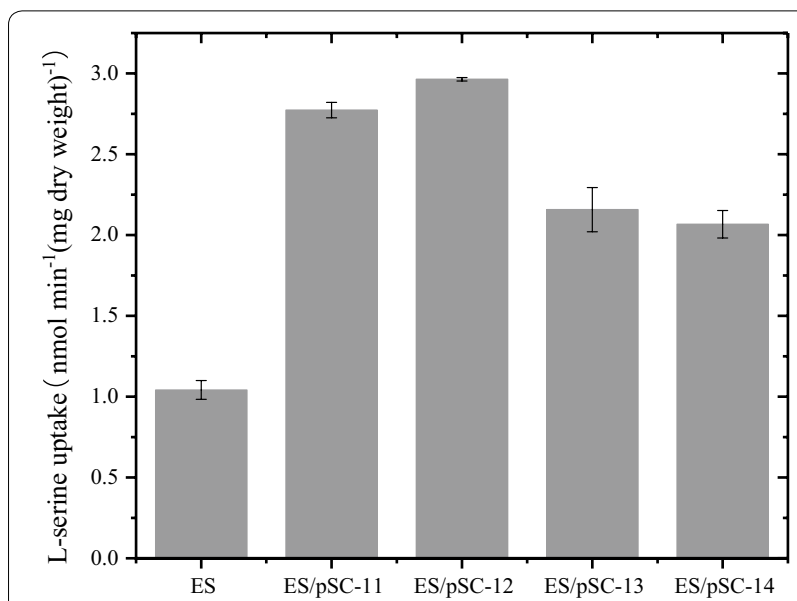

Fig. 3 L-serine influx was assayed in E. coli ES and mutants overexpressing the L-serine uptake genes. The data represent the means \pm SDs from three measurements. ES represents the parental strain

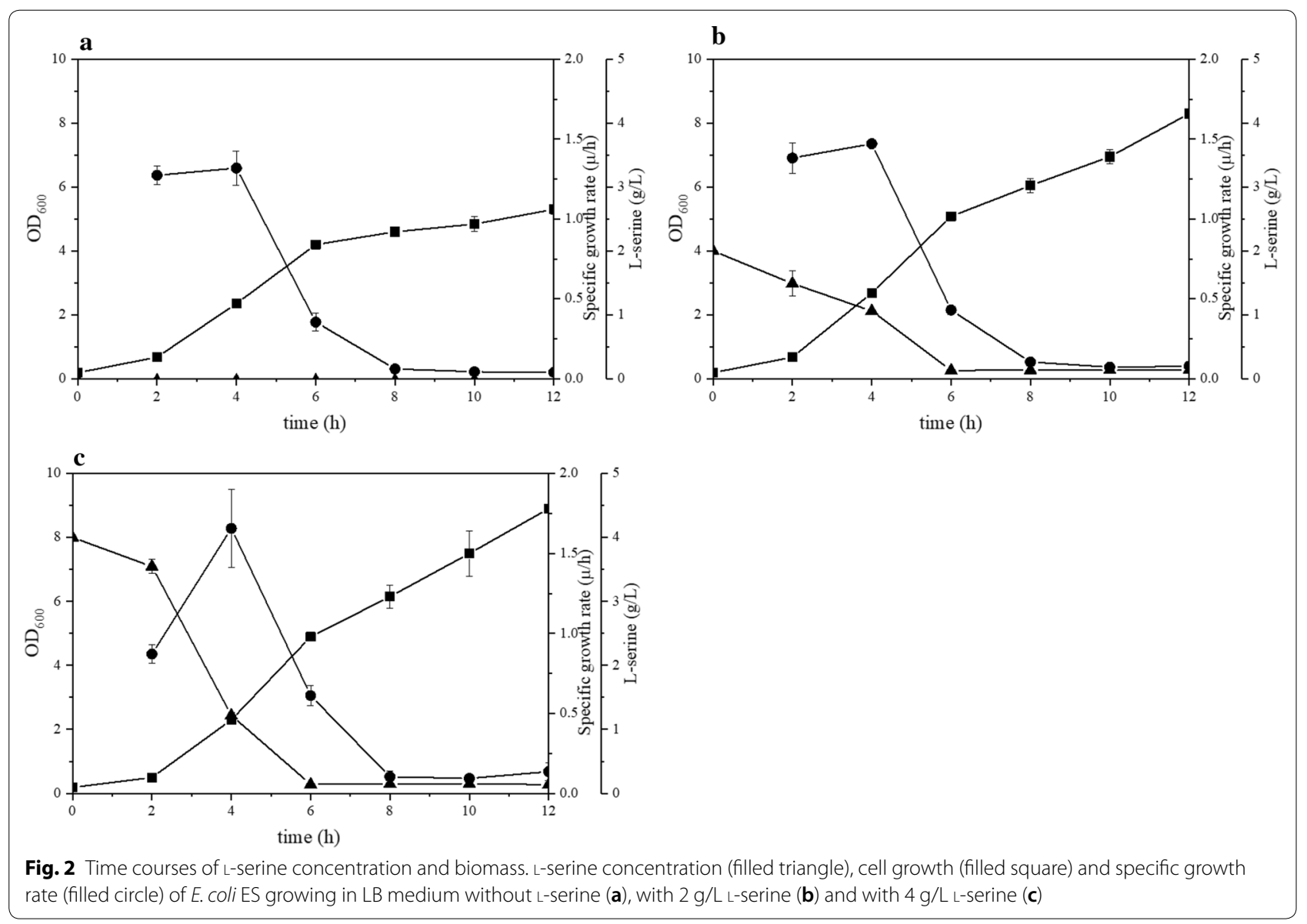


pSC-11, ES/pSC-14 and ES/pSC-13 was 2.983, 2.79, 2.3 and $2.166 \mathrm{nmol} \mathrm{min}^{-1}(\mathrm{mg} \text { dry weight })^{-1}$, respectively, increasing by $186 \%, 168 \%, 121 \%$ and $108 \%$ compared to that of the parent strain of ES $\left(1.04 \mathrm{nmol} \mathrm{min}{ }^{-1}\right.$ (mg dry weight $)^{-1}$ ). The time courses of L-serine uptake are shown in Additional file 2: Fig. S2. This result indicated that $c y c A$ and $s d a C$ played critical roles and that sst $T$ and $t d c C$ were also important in L-serine uptake activity.

\section{Effect of single-gene deletions on L-serine uptake}

The four genes, $s d a C, c y c A$, sst $T$ and $t d c C$, were knocked out, resulting in strains ES-1, ES-2, ES-3 and ES-4. As shown in Fig. 4 and Additional file 2: Fig. S3, the L-serine uptake activity (30 min) of ES-1 was $0.79 \mathrm{nmol} \mathrm{min}^{-1}$ ( $\mathrm{mg}$ dry weight $)^{-1}$, decreasing by $23 \%$ compared to that of the parent strain of ES $\left(1.04 \mathrm{nmol} \mathrm{min}^{-1}(\mathrm{mg} \text { dry weight })^{-1}\right)$. It was surprising that the L-serine uptake activity of ES-2, ES-4 and ES-3 increased by $77 \%, 48 \%$ and $33 \%$ compared to that of the control. This abnormal phenomenon was explored through a series of real-time quantitative reverse-transcription PCR (RT-qPCR) experiments. As shown in Fig. 5, deletion of the $c y c A$ and $t d c C$ genes led to a 1.76- and 1.15-fold increase in the relative expression of $s d a C$, respectively, which was consistent with the increase in L-serine uptake activity in the two mutants. However, the $s s t T$ mutants showed similar expression of $s d a C$ with increased L-serine uptake activity compared to ES. These results illustrated that certain regulatory mechanisms of the L-serine uptake system remain unknown.

\section{Effect of multigene deletions on L-serine uptake}

The above results demonstrated that $s d a C$ played a significant role in the L-serine uptake system, but the roles

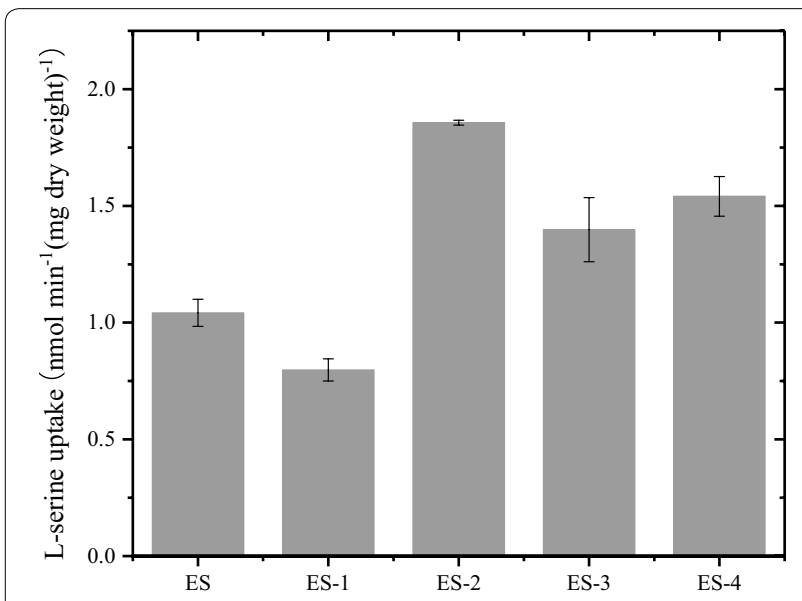

Fig. 4 L-serine influx was assayed in E. coli ES and single-gene knockout mutants. The data represent the means \pm SDs from three measurements. ES represents the parental strain. ES-1: ES $\triangle s d a C ; E S-2$ : ES $\triangle c y c A ; E S-3$ : ES $\triangle s s t T ;$ ES-4: ES $\triangle t d c C$

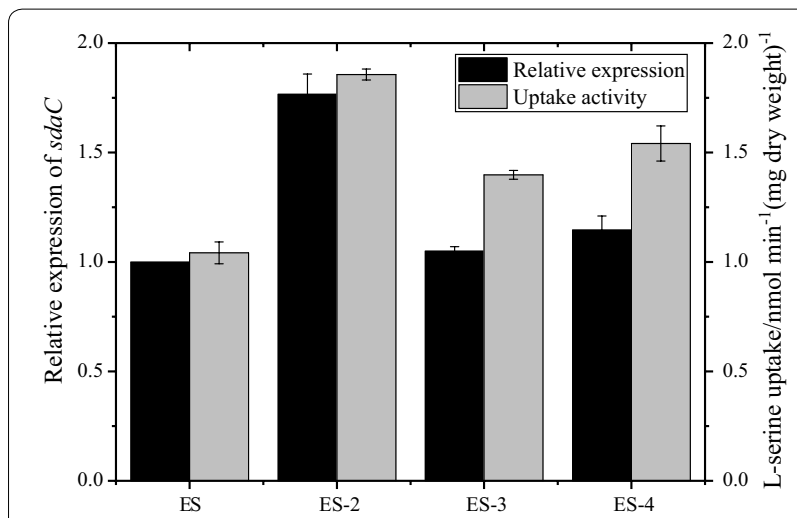

Fig. 5 Relative expression of sdaC in E. coli ES and single-gene knockout mutants. ES represents the parental strain, and the relative gene expression in ES was onefold. ES-2: ES $\triangle c y c$ A; ES-3: ES $\triangle$ sstT; ES-4: ES $\triangle t d c C$

of $c y c A$, sst $T$ and $t d c C$ in the uptake system remained unclear. Therefore, the three genes were knocked out combinatorially in the single-gene-deletion strain ES-1, resulting in seven multigene-deletion strains. The mutant strains were named ES-12 (ES $\Delta s d a C \Delta c y c A$ ), ES-13 (ES $\Delta s d a C \Delta s s t T$ ), ES-14 (ES $\Delta s d a C \Delta t d c C$ ), ES-123 (ES $\Delta s d a C \Delta c y c A \Delta s s t T), \quad \mathrm{ES}-124 \quad(\mathrm{ES} \Delta s d a C \Delta c y c A \Delta t d c C)$, ES-134 (ES $\Delta s d a C \Delta s s t T \Delta t d c C$ ) and ES-1234 (ES $\Delta s d a C \Delta c y c A \Delta s s t T \Delta t d c C$ ). As shown in Fig. 6 and Additional file 2: Fig. S4, among the double-gene-deletion strains, both strains ES-12 and ES-13 showed a low

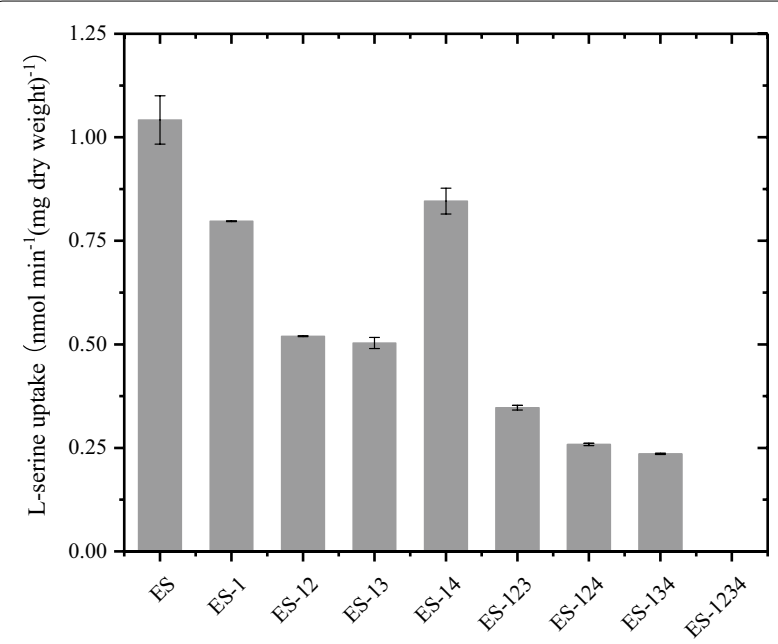

Fig. 6 L-serine influx was assayed in E. coli $\mathrm{ES}$ and multigene deletion mutants. The data represent the means \pm SDs from three measurements. ES represents the parental strain. ES-1: ES $\triangle s d a C_{\text {; }}$ ES-12: ES $\Delta s d a C \Delta c y c A$; ES-13: ES $\triangle s d a C \Delta s s t$; ES-14: ES $\triangle s d a C \Delta t d c C_{;}$ ES-123: ES $\triangle$ sdaC $\triangle c y c$ A $\triangle s s t T$, ES-124: ES $\triangle s d a C \Delta c y c A \Delta t d c C ;$ ES-134: ES $\triangle s d a C \triangle s s t T \Delta t d c C ;$ ES-1234: ES $\triangle s d a C \Delta c y c A \Delta s s t T \Delta t d c C$ 
L-serine uptake activity of nearly $0.50 \mathrm{nmol} \mathrm{m^{-1 }}(\mathrm{mg}$ dry weight $)^{-1}$, decreasing by $52 \%$ compared to that of ES. However, another double-gene deletion strain, ES-14, showed $0.846 \mathrm{nmol} \mathrm{m^{-1 }}(\mathrm{mg} \text { dry weight })^{-1}$ L-serine uptake activity, which was similar to that of ES-1. Among the triple-gene deletion mutants, the L-serine uptake activity of ES-123 was $0.347 \mathrm{nmol} \mathrm{min}{ }^{-1}$ (mg dry weight $)^{-1}$. ES-124 and ES-134 showed an L-serine uptake activity of nearly $0.24 \mathrm{nmol} \mathrm{min}^{-1}$ (mg dry weight) ${ }^{-1}$, decreasing by $76 \%$ compared to that of ES. Finally, when all four genes were deleted (ES-1234), the L-serine uptake activity decreased to near zero, which implied that the strain could not import extracellular L-serine effectively.

\section{The impact of the deletion of L-serine uptake genes on growth and L-serine production in shake flask fermentation}

To evaluate the L-serine production capability of the L-serine uptake system mutants, the mutant strains were transformed with the plasmid pSC-08 containing the $\mathrm{L}$-serine synthesis genes $\operatorname{ser} A^{f r}, \operatorname{ser} B$ and $\operatorname{ser} C$ and the 3-phosphoglycerate kinase gene $p g k$ and shake flask fermentation was performed. Among single-gene deletion mutants, deletion of $s d a C$, sst $T$ and $t d c C$ had a slight effect on the density of the cell cultures (Fig. 7), including that all strains in which $c y c A$ was deleted showed poor growth, and ES-2/pSC-08 showed a low final $\mathrm{OD}_{600}$ of 2.19 , which was $30 \%$ less than that of ES/ pSC-08 $\left(\mathrm{OD}_{600} \sim 2.9\right)$. The strains exhibited poor growth when more genes were knocked out. For example, the final $\mathrm{OD}_{600}$ values of ES-1/pSC-08, ES-13/pSC-08 and
ES-134/pSC-08 were 3.2-, 2.43- and 2.23, respectively, which were 1.1-, 0.82 - and 0.77 -fold the value for ES/ pSC-08. respectively.

In addition, as shown in Fig. 7, the strains with lower L-serine uptake activity exhibited higher L-serine production. For instance, ES-1/pSC-08, ES-13/pSC-08 and ES-134/pSC-08 showed 23\%, $48 \%$ and $77 \%$ lower L-serine uptake activity and 69\%, 196\% and 242\% higher L-serine production, respectively, than the control strain ES/ pSC-08 (1.04 $\mathrm{nmol} \mathrm{min}^{-1}$ (mg dry weight $)^{-1}, 130 \mathrm{mg} / \mathrm{L}$ ). ES-134/pSC-08 achieved the highest L-serine production $(445 \mathrm{mg} / \mathrm{L})$ in shake flask fermentation. However, ES-1234/pSC-08, which had nearly no L-serine uptake activity, produced only $384 \mathrm{mg} / \mathrm{L} \mathrm{L}$-serine and showed the poorest cell growth.

\section{Fed-batch fermentation in a 5 -L fermenter}

The four high-yield strains in shake flask fermentation, namely, ES-1/pSC-08, ES-13/pSC-08, ES-134/pSC-08 and ES-1234/pSC-08, were selected for a 36-h fed-batch fermentation in a 5-L fermenter. As shown in Fig. 8 and Additional file 3: Table S1, ES-1/pSC-08 produced $23.8 \mathrm{~g} / \mathrm{L} \mathrm{L}$-serine with a yield of $0.25 \mathrm{~g} \mathrm{~L}$-serine/g glucose. The production of ES-13/pSC-08 further increased to $29.6 \mathrm{~g} / \mathrm{L}$ with a yield of $0.31 \mathrm{~g} \mathrm{L-serine/g}$ glucose. As expected, the triple-deletion mutant strain ES-134/ pSC-08 showed the highest production of $34.8 \mathrm{~g} / \mathrm{L}$ with a yield of $0.32 \mathrm{~g} \mathrm{~L}$-serine/g glucose, increasing by $46 \%$ compared to that of ES-1/pSC-08. The concentration of L-serine detected at the end of the ES-1234/pSC-08 fedbatch culture was $26.3 \mathrm{~g} / \mathrm{L}$, which was similar to that of

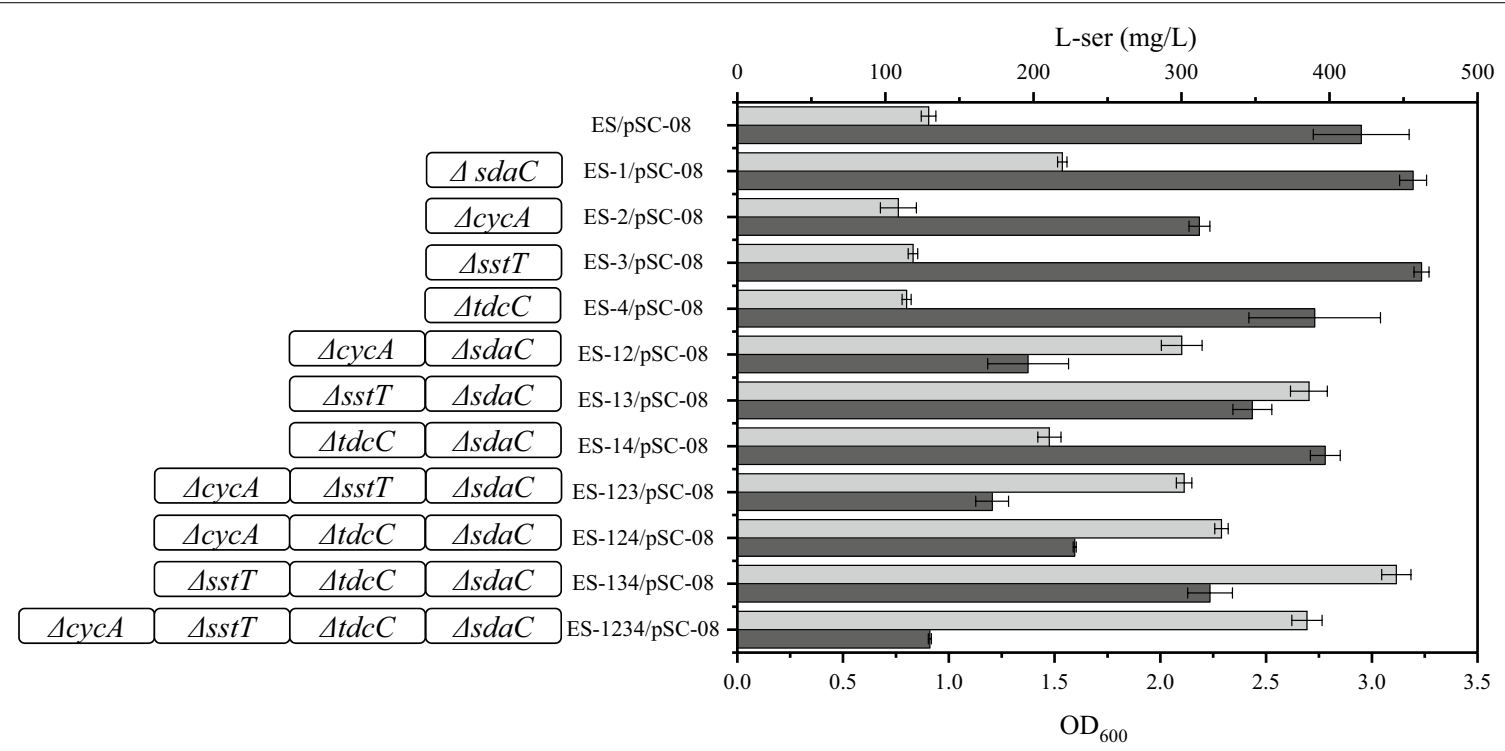

Fig. 7 Biomass and L-serine production of different strains in shake flask fermentations. The data represent the means \pm SDs from three measurements. The genotype of the strains and the biomass (dark gray) and L-serine production (light gray) of different strains are shown 

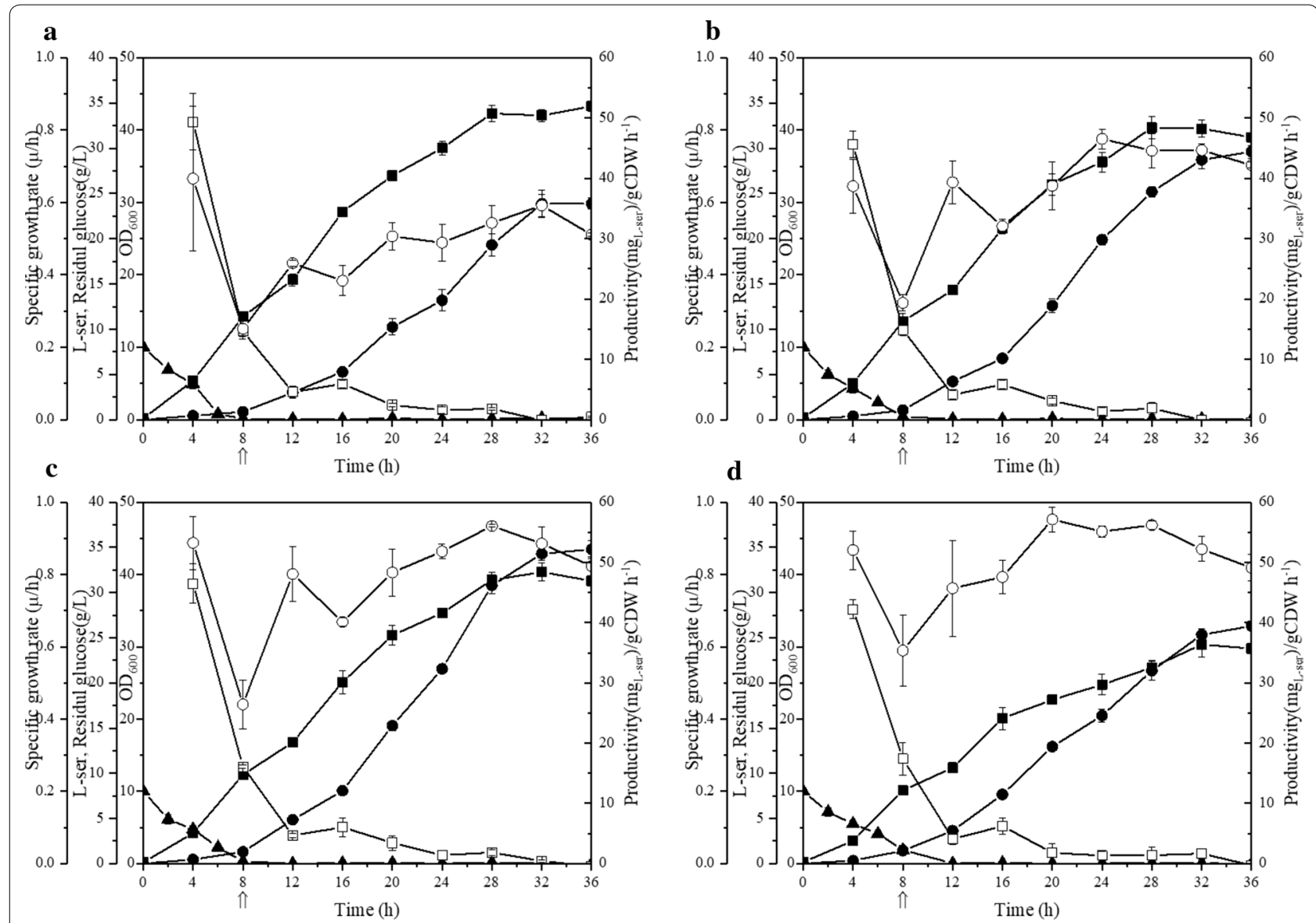

Fig. 8 Fed-batch fermentations of ES-1/pSC-08, ES-13/pSC-08, ES-134/pSC-08 and ES-1234/pSC-08. ES-1/pSC-08 (a), ES-13/pSC-08 (b), ES-134/ pSC-08 (c), ES-1234/pSC-08 (d). Cell growth (filled square), L-serine concentration (filled circle), residual glucose concentration (up filled triangle), specific growth rate (open square), and L-serine productivity (open circle) are shown; the arrow at $8 \mathrm{~h}$ indicates the starting point of induction

ES-1/pSC-08, due to the lowest biomass $\left(\mathrm{OD}_{600} \sim 30\right)$ of ES-1234/pSC-08.

During the effective L-serine production time $(12-$ $36 \mathrm{~h})$, the productivity of ES-1/pSC-08, ES-13/pSC08, ES-134/pSC-08 and ES-134/pSC-08 was in the range of 23-36, 31-47, 40-56 and 46-57 $\mathrm{mg} \mathrm{L}$-serine/g CDW $\mathrm{h}^{-1}$, respectively (Fig. 8). Additionally, ES-134/ pSC-08 achieved the highest L-serine titer. However, the L-serine production of ES-1234/pSC-08 was affected by its lowest $\mathrm{OD}_{600}$ although it showed the highest L-serine productivity.

\section{Discussion}

L-Serine is an important biochemical building block, and the microbial production of L-serine from glucose provides a cost-competitive method. Previous studies focused on enhancing the metabolic flux of $\mathrm{L}$-serine and inhibiting L-serine degradation. However, in this study, it was found that external L-serine was reimported into the E. coli, and nearly $4 \mathrm{~g} / \mathrm{L} \mathrm{L}$-serine could be consumed at
$6 \mathrm{~h}$ of cultivation. This may hinder high production of the L-serine-producing strain. The L-serine uptake system was deleted to prevent this phenomenon.

Four genes, $s d a C, c y c A$, sst $T$ and $t d c C$, were reported to be related to L-serine uptake. Only $s d a C$ has been described as a highly specific L-serine transporter and belongs to the $\mathrm{H}^{+}$-symporter family $[16,17]$. In this study, deletion of $s d a C$ resulted in a $23 \%$ decrease in L-serine uptake (Fig. 4). The abnormally increasing influx of $\mathrm{L}$-serine was attributed to the elevated expression of $s d a C$ in the other single-gene mutations. $c y c A$, which also belongs to the $\mathrm{H}^{+}$-symporter family, is the main alanine carrier and participates in L-serine and glycine uptake simultaneously in E. coli [18-20]. Among the singlegene mutations, only the $c y c A$ mutation led to a decline in the final $\mathrm{OD}_{600}$ of the cell culture. This may be due to the defective uptake of alanine when the transporter of alanine, $c y c A$, was deleted, thus affecting cell growth. sst $T$ is a $\mathrm{Na}^{+}$-dependent carrier and mediates the uptake of L-threonine and L-serine $[17,21]$. Notably, $\mathrm{t} d c C$ is an 
$\mathrm{H}^{+}$-dependent threonine transporter and is involved in L-serine transport under anaerobic conditions [22, 23]. Nevertheless, in this study, L-serine uptake activity increased $108 \%$ in shake flask fermentation when $t d c C$ was overexpressed with the promoter PR under aerobic conditions. The related regulatory mechanisms need further experiments to explore. These data indicated that $s d a C$ was the most critical gene of the L-serine uptake system and that there was coordinated regulation among various L-serine-related genes.

This study provides evidence that low L-serine uptake activity contributes to high L-serine production, and similar gains have been achieved in other amino acid productions processes according to previous studies. For example, the L-threonine uptake rates of strains VL334 pYN7, ATCC 98082 pYN7 and BKIIMB-3996 pVIC40 were $4.7,2.8$ and $1.9 \mathrm{nmol} \mathrm{min}^{-1}$ (mg dry weight) ${ }^{-1}$, respectively, producing 9,20 and $80 \mathrm{~g} / \mathrm{L}$ L-threonine [14]. In this study, the strains ES-1 and ES-134 showed decreases in L-serine uptake activity of $30 \%$ and $75 \%$, respectively, and increases in $\mathrm{L}$-serine production of $67 \%$ and $245 \%$, respectively, in shake flask fermentations (Figs. 6 and 7). The production of ES-134 was further increased to $34.8 \mathrm{~g} / \mathrm{L}$ with a yield of $0.32 \mathrm{~g} \mathrm{~L}$-serine $/ \mathrm{g}$ glucose during a 36-h fed-batch bioconversion (Fig. 8). Notably, cell growth was affected when the L-serine uptake genes were deleted, and the production was subsequently indirectly impacted. For instance, ES-1234, which could barely import extracellular L-serine, only produced $26.3 \mathrm{~g} / \mathrm{L} \mathrm{L}$-serine as a result of its poor growth. Therefore, the growth of the strain is an important factor during fermentation engineering.

\section{Conclusion}

Deletion of the L-serine uptake system led to significant enhancement of L-serine production. The reduction of L-serine uptake activity could benefit L-serine production. The data show that $s d a C$ is a key gene in the L-serine uptake system and that deletion of $s d a C$ is important for improving L-serine production. Our studies have demonstrated that modification of the L-serine uptake system may be a useful strategy for improving L-serine production.

\section{Materials and methods}

\section{Bacterial strains and plasmids}

The E. coli ES strain is a laboratory stock that is a $s d a A$ and glyA double-gene knockout mutant derived from wild-type $E$. coli W3110. In the present study, four L-serine uptake genes, namely, $s d a C, c y c A$, sst $T$ and $t d c C$, were knocked out individually or combinatorially from the genome of E. coli ES. The primers shown in Additional file 4: Table S2, were used to conduct single- or multigene knockout mutations based on a previously reported method [24]. The strains constructed in this study were verified by sequencing. All strains are listed in Table 1 .

The low copy number vector pSC is a laboratory stock plasmid and contains the temperature-sensitive lambda-repressor cItS857 gene and the lambda PR and PL promoters. The expression plasmid pSC-08 (pSCPR-serB-PL-ser $A^{f r}$-PR-serC-PL-pgk with the p15A origin gene, Additional file 5: Fig. S5) is a laboratory stock plasmid and contains the feedback-insensitive $\operatorname{ser} A^{f r}$ (H334A, $\mathrm{D} 346 \mathrm{~A})$ gene, the $\operatorname{ser} C$ and $\operatorname{ser} B$ genes, and the glucose metabolism-related gene $p g k$. The plasmids pKD13, pKD46 and pCP20 are helper plasmids and are used for the construction of knockout mutants.

In this study, the plasmids pSC-11, pSC-12, pSC-13 and pSC-14 were derived from the plasmid pSC. All L-serine uptake-related genes, namely, $s d a C, c y c A$, sst $T$ and $t d c C$, were cloned from the chromosomal DNA of $E$. coli W3110. For example, the primers $s d a C$-AvrII and $s d a C$ PvuII (Additional file 4: Table S2) were used to amplify $s d a C$ by PCR. Then, the amplified fragments were ligated into the pMD-19 vector through TA cloning. After DNA sequencing, $s d a C$ was subcloned into the plasmid pSC under the control of the $\mathrm{PR}$ promoter to create the plasmid pSC- 11 . The plasmids pSC-12, pSC-13 and pSC14 were obtained by inserting $c y c A$, sst $T$ and $\operatorname{tdcC}$ into the plasmid pSC, respectively, using the same method described above. All constructed plasmids are listed in Table 2 .

\section{Media}

LB medium $(10 \mathrm{~g} / \mathrm{L}$ tryptone, $10 \mathrm{~g} / \mathrm{L} \mathrm{NaCl}, 5 \mathrm{~g} / \mathrm{L}$ yeast extract) was used to culture the strains for the serine uptake assays. For L-serine production, minimal M9

\section{Table 1 Strains used in this study}

\begin{tabular}{|c|c|c|}
\hline Strain & Description & Source or reference \\
\hline W3110 & K-12 wild-type (ATCC 27325) & $\begin{array}{l}\text { Genetimes ExCell Tech- } \\
\text { nology, Inc }\end{array}$ \\
\hline ES & W3110 ( $\triangle s d a A, \triangle g l y A)$ & Stock in lab \\
\hline ES-1 & $\mathrm{ES}(\triangle \mathrm{sdaC})$ & This work \\
\hline ES-2 & $\mathrm{ES}(\triangle c y c A)$ & This work \\
\hline ES-3 & $\mathrm{ES}(\Delta s s t T)$ & This work \\
\hline ES-4 & $\mathrm{ES}(\Delta t d c C)$ & This work \\
\hline ES-12 & $\mathrm{ES}(\triangle \mathrm{sdaC}, \Delta c y c A)$ & This work \\
\hline ES-13 & $\mathrm{ES}(\Delta s d a C, \Delta s s t))$ & This work \\
\hline ES-14 & $\mathrm{ES}(\Delta s d a C, \Delta t d c C)$ & This work \\
\hline ES-123 & $\mathrm{ES}(\Delta s d a C, \Delta c y c A, \Delta s s t T)$ & This work \\
\hline ES-124 & $\mathrm{ES}(\Delta s d a C, \Delta c y c A, \Delta t d c C)$ & This work \\
\hline ES-134 & $\mathrm{ES}(\Delta s d a C, \Delta s s t T, \Delta t d c C)$ & This work \\
\hline ES-1234 & $\mathrm{ES}(\Delta s d a C, \Delta c y c A, \Delta s s t T, \Delta t d c C)$ & This work \\
\hline
\end{tabular}


Table 2 Plasmids used in this study

\begin{tabular}{ll}
\hline Plasmid & Relevant characteristics \\
\hline pKD13 & Smp and kan markers \\
pKD46 & amp markers, temperature-sensitive \\
pCP20 & amp and Ch/ markers, temperature-sensitive \\
pMD-19 & PCR cloning vector \\
pSC & Low copy number, kan marker, p15A replicon, lambda PR and PL promoters \\
pSC-08 & pSC derivative, carrying serA ${ }^{\text {fr }}$ under PL promoter, serB under PR promoter, serC under PR promoter \\
pSC-11 & and pgk under PL promoter \\
pSC-12 & PSC derivative, carrying sdaC under PR promoter in lab \\
pSC-13 & pSC derivative, carrying cycA under PR promoter \\
pSC-14 & pSC derivative, carrying sstT under PR promoter \\
\hline
\end{tabular}

medium (6.8 g/L Na $\mathrm{HPO}_{4}, 3 \mathrm{~g} / \mathrm{L} \mathrm{KH}_{2} \mathrm{PO}_{4}, 0.5 \mathrm{~g} / \mathrm{L}$ $\mathrm{NaCl}, 1 \mathrm{~g} / \mathrm{L} \mathrm{NH}_{4} \mathrm{Cl}, 0.015 \mathrm{~g} / \mathrm{L} \mathrm{CaCl}_{2} \cdot 2 \mathrm{H}_{2} \mathrm{O}, 0.49 \mathrm{~g} / \mathrm{L}$ $\mathrm{MgSO}_{4} \cdot 7 \mathrm{H}_{2} \mathrm{O}$ and $\left.2.8 \times 10^{-4} \mathrm{~g} / \mathrm{L} \mathrm{MgSO}_{4} \cdot 7 \mathrm{H}_{2} \mathrm{O}\right)$ with $2 \mathrm{~g} / \mathrm{L}$ yeast extract and $9 \mathrm{~g} / \mathrm{L}$ glucose was used with a shake flask. Fed-batch cultures contained $3 \mathrm{~g} / \mathrm{L}$ $\mathrm{MgSO}_{4} \cdot 7 \mathrm{H}_{2} \mathrm{O}, 0.017 \mathrm{~g} / \mathrm{L} \mathrm{CaCl}_{2} \cdot 2 \mathrm{H}_{2} \mathrm{O}, 1 \mathrm{~g} / \mathrm{L} \mathrm{NaCl}$, $5 \mathrm{~g} / \mathrm{L}\left(\mathrm{NH}_{4}\right)_{2} \mathrm{SO}_{4}, 0.07 \mathrm{~g} / \mathrm{L} \mathrm{FeSO}_{4} \cdot 7 \mathrm{H}_{2} \mathrm{O}, 0.11 \mathrm{~g} / \mathrm{L} \mathrm{Na}-$ citrate $\cdot 2 \mathrm{H}_{2} \mathrm{O}, 2 \mathrm{~g} / \mathrm{L}$ yeast extract, $8 \mathrm{~g} / \mathrm{L}$ glucose and $1.5 \mathrm{~mL} / \mathrm{L} 1000 \times$ mother liquor of a composite additive of trace elements $\left(7 \mathrm{~g} / \mathrm{L} \mathrm{CoCl}_{2} \cdot 6 \mathrm{H}_{2} \mathrm{O}, 2.5 \mathrm{~g} / \mathrm{L}\right.$ $\mathrm{CuSO}_{4} \cdot 5 \mathrm{H}_{2} \mathrm{O}, 25 \mathrm{~g} / \mathrm{L} \mathrm{H}_{3} \mathrm{BO}_{3}, 16 \mathrm{~g} / \mathrm{L} \mathrm{MnCl}_{2} \cdot 4 \mathrm{H}_{2} \mathrm{O}$, $\left.1.5 \mathrm{~g} / \mathrm{L} \mathrm{Na}_{2} \mathrm{MoO}_{4} \cdot 2 \mathrm{H}_{2} \mathrm{O}, 3 \mathrm{~g} / \mathrm{L} \mathrm{ZnSO}_{4} \cdot 7 \mathrm{H}_{2} \mathrm{O}\right)$.

\section{Shake flask and fed-batch fermentation}

For shake flask studies, a single clone was first grown in $5 \mathrm{~mL}$ of LB for $12-14 \mathrm{~h}$, and then, $5 \mathrm{~mL}$ was transferred to $100 \mathrm{~mL}$ of M9 medium with $2 \mathrm{~g} / \mathrm{L}$ yeast extract and $9 \mathrm{~g} / \mathrm{L}$ glucose and grown in a 500-mL shake flask at $30{ }^{\circ} \mathrm{C}$ and $200 \mathrm{rpm}$. Each culture was induced after $3 \mathrm{~h}$ by heating to $38{ }^{\circ} \mathrm{C}$. The shake flask studies were replicated three or more times.

All fed-batch fermentations were conducted in a 5-L bioreactor (Biostat A Plus, Sartorius Stedim, Germany). A single clone was precultured in $50 \mathrm{~mL}$ of $\mathrm{LB}$ medium and shaken at $33{ }^{\circ} \mathrm{C}$ and $200 \mathrm{rpm}$ for 12 to $14 \mathrm{~h}$. The culture was inoculated into $2.5 \mathrm{~L}$ of fermentation medium at a $1: 20(\mathrm{v} / \mathrm{v})$ inoculum ratio with an initial temperature of $33{ }^{\circ} \mathrm{C}$. L-serine production was induced at $8 \mathrm{~h}$ by heating to $38{ }^{\circ} \mathrm{C}$. The agitation, air supplementation and feed rate were changed to maintain the dissolved oxygen (DO) concentrations above $30 \%$ saturation. The $\mathrm{pH}$ was controlled at 6.8 using $30 \%(\mathrm{w} / \mathrm{v}) \mathrm{NH}_{3}{ }^{*} \mathrm{H}_{2} \mathrm{O}$. The DO-stat feeding strategy was employed to supply exhausted nutrients to the fermenter. The feeding solution contained $40 \%(\mathrm{w} / \mathrm{w})$ glucose.

\section{Analysis methods}

The cell density was determined from the $\mathrm{OD}_{600}$ by using a UV/vis spectrophotometer (DU730, Beckman, Germany) and converted into the cell dry weight (CDW) using a precalibrated conversion factor of 0.5 . Glucose was measured offline based on glucose oxidase (GOx) binding to electrode transducers, which determines glucose based on amperometric (anodic) monitoring of liberated hydrogen peroxide, by an SBA sensor machine (Institute of Microbiology, Shandong, China) [25].

For quantification of L-serine, the culture was centrifuged $(16,904 \times g$ for $10 \mathrm{~min})$ and filtered through a 0.22 $\mu \mathrm{m}$ syringe filter to prepare cell-free supernatant. Then, the supernatant was precolumn derived as described in previous research [26]. The samples obtained were used for HPLC analysis with a Shimadzu Separations module connected to a Shimadzu SPD-M20A detector set to $256 \mathrm{~nm}$. The samples were separated on an Agilent Extend C-18 column $(250 \mathrm{~mm} \times 4.6 \mathrm{~mm}, 5 \mu \mathrm{m})$ with $0.05 \mathrm{~mol} / \mathrm{L}$ sodium acetate $(\mathrm{pH} 6.50 \pm 0.05)$ (mobile phase A) and methanol/acetonitrile/water (20:60:20, $\mathrm{v} / \mathrm{v} / \mathrm{v}$ ) (mobile phase B). The following gradient was used at a flow rate of $0.8 \mathrm{~mL} / \mathrm{min}$ for $25 \mathrm{~min}$ : from $0 \mathrm{~min}$ to $11 \mathrm{~min}, 85 \%$ solvent $\mathrm{A}+15 \%$ solvent $\mathrm{B}$; at $11 \mathrm{~min}$, the ratio of solvent $B$ increased to $100 \%$; at $12 \mathrm{~min}, 0 \%$ solvent $A+100 \%$ solvent $B$; from 15 to $17 \mathrm{~min}$, the ratio of solvent B decreased to $15 \%$; and from $17 \mathrm{~min}$ to $25 \mathrm{~min}$, $85 \%$ solvent $\mathrm{A}+15 \%$ solvent $\mathrm{B}$.

\section{L-Serine uptake activity assay}

Cells were cultured in $200 \mathrm{~mL}$ of $\mathrm{LB}$ medium to $\mathrm{OD}_{600} \sim 2.0$ at $37^{\circ} \mathrm{C}$ with shaking at $200 \mathrm{rpm}$, centrifuged and washed twice with Buffer X $\left(7.2 \mathrm{mmol} / \mathrm{L} \mathrm{K}_{2} \mathrm{HPO}_{4}\right.$, $2.8 \mathrm{mmol} / \mathrm{L} \mathrm{KH}_{2} \mathrm{PO}_{4}, 100 \mathrm{mmol} / \mathrm{L} \mathrm{NaCl}$ ) followed by centrifugation at $8608 \times g$ and $4{ }^{\circ} \mathrm{C}$ for $3 \mathrm{~min}$. Eventually, the cells were resuspended in $50 \mathrm{~mL}$ of Buffer $\mathrm{X}$ containing 
an additional $10 \mathrm{mmol} / \mathrm{L} \mathrm{L}$-serine and $20 \mathrm{mmol} / \mathrm{L} \mathrm{glu}$ cose and cultivated at $37^{\circ} \mathrm{C}$ for the L-serine uptake assay. Samples were collected every $5 \mathrm{~min}$ and centrifuged at $8608 \times g$ at $4{ }^{\circ} \mathrm{C}$ for $2 \mathrm{~min}$. The cell-free culture supernatant was collected and assayed by HPLC. The L-serine uptake activity was defined as the nanomoles of serine taken up per milligram of dry cell weight according to a previous method $[27,28]$.

\section{Total RNA isolation, CDNA synthesis and qPCR conditions}

First, $500 \mu \mathrm{L}$ samples in log-phase were collected and immediately frozen in liquid nitrogen. Then, the cells were used for RNA isolation with a UNlQ-10 Column TRIzol Total RNA Isolation Kit (Sangon Biotech, China). The purity of the total extracted RNA was analysed by a NanoDrop spectrophotometer (NanoDrop 2000c, Thermo Scientific, USA), and the integrity was checked by electrophoresis on a $1.5 \%$ agarose gel. RNA samples were subjected to cDNA synthesis using a High Capacity cDNA Reverse Transcription Kit (Thermo Scientific, USA).

qPCRs were performed using a StepOnePlus Real-Time PCR System (ABI, Foster, CA, USA). The primer pairs used for amplifying the genes are shown in Additional file 6: Table S3. The PCR mixture consisted of $10 \mu \mathrm{L}$ of $2 \times$ SybrGreen qPCR Master Mix, $20 \mu \mathrm{M}$ forward and reverse primers, 20 ng of cDNA template and nucleasefree water in a total volume of $20 \mu \mathrm{L}$. Thermocycling was performed using the following conditions: $3 \mathrm{~min}$ at $95^{\circ} \mathrm{C}$ followed by 40 cycles alternating between $5 \mathrm{~s}$ at $95^{\circ} \mathrm{C}$ and $30 \mathrm{~s}$ at $60^{\circ} \mathrm{C}$. Melting curve analysis $\left(60-95^{\circ} \mathrm{C}\right)$ was routinely performed after 45 cycles to verify primer specificity. The $2^{-\Delta \Delta C t}$ method was used to calculate the relative expression level of the target genes [29].

\section{Supplementary information}

Supplementary information accompanies this paper at https://doi. org/10.1186/s12934-020-01323-2.

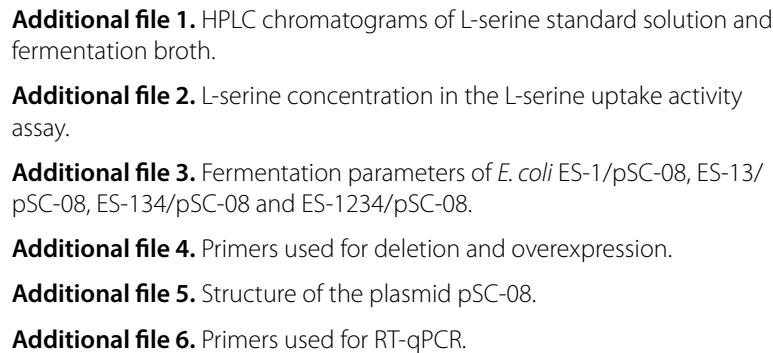

\section{Abbreviations}

Fr: Feedback-inhibition resistance; SHMT: L-serine hydroxymethyltransferase; GABA: Aminobutyric acid; LB: Luria-Bertani; GOx: Glucose oxidase; RT-qPCR: Real-time quantitative reverse-transcription PCR; DO: Dissolved oxygen; CDW: Cell dry weight; HPLC: High-performance liquid chromatography.
Acknowledgements

Not applicable.

\section{Authors' contributions}

CW and BS carried out the uptake gene deletion and L-serine uptake activity assay. CW performed the RT-qPCR experiment and L-serine fermentation. CW, JW and ZZ analysed the data. CW, JW, ZZ and JS conceived the study and reviewed the manuscript. All authors read and approved the final manuscript.

\section{Funding}

This work was financially supported by the National Natural Science Foundation of China (No. 31300048).

\section{Availability of data and materials}

All data generated and analysed during this study are included in this published article and its additional files.

Ethics approval and consent to participate

Not applicable.

\section{Consent for publication}

Not applicable.

\section{Competing interests}

The authors declare that they have no competing interests.

\section{Author details}

${ }_{1}^{1}$ Biorefinery Laboratory, Shanghai Advanced Research Institute, Chinese Academy of Sciences, 99 Haike Road, Shanghai 201210, China. ${ }^{2}$ University of Chinese Academy of Sciences, 19 Yuquan Road, Beijing 100049, China. ${ }^{3}$ College of Food Science and Technology, Nanjing Agricultural University, 1 Weigang Road, Nanjing 210095, China. ${ }^{4}$ College of Life Science, Shihezi University, 221 Beisi Road, Shihezi 832003, China. ${ }^{5}$ School of Life Science and Technology, ShanghaiTech University, Shanghai 201210, China.

Received: 15 November 2019 Accepted: 4 March 2020

Published online: 14 March 2020

\section{References}

1. Eggeling L. L-Serine and glycine. In: Wendisch VF, editor. Amino acid biosynthesis pathways, regulation and metabolic engineering, vol. 5 . Springer: Berlin; 2007. p. 259-72 (Steinbüchel L (Series Editor): Microbiology Monographs)

2. Becker J, Wittmann C. Systems and synthetic metabolic engineering for amino acid production - the heartbeat of industrial strain development. Curr Opin Biotechnol. 2012;23:718-26.

3. Zhang X, Xu G, Shi J, Koffas MAG, XU Z. Microbial production of L-serine from renewable feedstocks. Trends Biotechnol. 2018;36:700-12.

4. Peters-Wendisch P, Stolz M, Etterich H, Kennerknecht N, Sahm H, Eggeling L. Metabolic engineering of Corynebacterium glutamicum for L-serine production. Appl Environ Microbiol. 2005;71:7139-44.

5. Stolz M, Peters-Wendisch P, Etterich H, Gerharz T, Faurie R, Sahm H, Fersterra $\mathrm{H}$, Eggeling L. Reduced folate supply as a key to enhanced L-serine production by Corynebacterium glutamicum. Appl Environ Microbiol. 2007:73:750-5.

6. Zhu Q, Zhang X, Luo Y, Guo W, Xu G, Shi J, Xu Z. L-Serine overproduction with minimization of by-product synthesis by engineered Corynebacterium glutamicum. Appl Microbiol Biotechnol. 2015;99:1665-73.

7. Lai S, Zhang Y, Liu S, Liang Y, Shang X, Chai X, Wen T. Metabolic engineering and flux analysis of Corynebacterium glutamicum for L-serine production. Sci China Life Sci. 2012;55:283-90.

8. Li Y, Chen GK, Tong XW, Zhang HT, Liu XG, Liu YH, Lu FP. Construction of Escherichia coli strains producing L-serine from glucose. Biotechnol Lett. 2012:34:1525-30

9. Zhang Y, Kang P, Liu S, Zhao Y, Wang Z, Chen T. glyA gene knock-out in Escherichia coli enhances L-serine production without glycine addition. Biotechnol Bioprocess Eng. 2017;22:390-6. 
10. Gu P, Yang F, Su T, Li F, Li Y, Qi Q. Construction of an L-serine producing Escherichia coli via metabolic engineering. J Ind Microbiol Biotechnol. 2014:41:1443-50

11. Mundhada H, Schneider $K$, Christensen HB, Nielsen AT. Engineering of high yield production of L-serine in Escherichia Coli. Biotechnol Bioeng 2016;113:807-16.

12. Mundhada H, Seoane JM, Schneider K, Koza A, Christensen HB, Klein T, Phaneuf PV, Herrgard M, Feist AM, Nielsen AT. Increased production of L-serine in Escherichia coli through adaptive laboratory evolution. Metab Eng. 2017;39:141-50.

13. Zhijun Z, Sheng C, Dan W, Jing W, Jian C. Effect of gene knockouts of L-tryptophan uptake system on the production of L-tryptophan in Escherichia coli. Process Biochem. 2012:47:340-4.

14. Kruse DSS, Krämer R, Burkovski A. Analysis of threonine uptake in Escherichia coli threonine production strains. Biotechnol Lett. 2001;23:401-4.

15. Zhao Z, Ding JY, Ma WH, Zhou NY, Liu SJ. Identification and characterization of gamma-aminobutyric acid uptake system GabPCg (NCgl0464) in Corynebacterium glutamicum. Appl Environ Microbiol. 2012;78:2596-601.

16. ZhongQi SHAO RTLaEBN. Sequencing and characterization of the sdaC gene and identification of the sdaCB operon in Escherichia coli K12. Eur J Biochem. 1994;222:901-7.

17. Ogawa WKT, Tsuda M, Mizushima T, Tsuchiya T. Isolation and characterization of an Escherichia coli mutant lacking the major serine transporter_ and cloning of a serine transporter gene. Biochem J. 1997;122:1241-5.

18. Wargel RJ, Shadur CA, Neuhaus FC. Mechanism of D-cycloserine action: transport systems for D-alanine, D-cycloserine, L-alanine, and glycinel. J Bacteriol. 1970;103:778-88.

19. Robbins JC, Oxender DL. Transport systems for alanine, serine, and glycine in Escherichia coli K-12. J Bacteriol. 1973;116:12.

20. Schneider F, Kramer R, Burkovski A. Identification and characterization of the main beta-alanine uptake system in Escherichia coli. Appl Microbiol Biotechnol. 2004;65:576-82.
21. Kim YM, Ogawa W, Tamai E, Kuroda T, Mizushima T, Tsuchiya T. Purification, reconstitution, and characterization of NaVSerine symporter, SstT, of Escherichia coli. J Biochem. 2002;132:71-6.

22. Goss TJ, Schweizer HP, Datta PR. Molecular characterization of the tdc operon of Escherichia coli K-12. J Bacteriol. 1988;170:5352-9.

23. Ganduri YL, Sadda SR, Datta MW, Jambukeswaran RK, Datta P. TdcA, a transcriptional activator of the $\mathrm{tdCABC}$ operon of Escherichia coil, is a member of the LysR family of proteins. Mol Gen Gene. 1993;240:395-402.

24. Baba T, Ara T, Hasegawa M, Takai Y, Okumura Y, Baba M, Datsenko KA, Tomita M, Wanner BL, Mori H. Construction of Escherichia coli K-12 inframe, single-gene knockout mutants: the Keio collection. Mol Syst Biol. 2006;2006(2):0008.

25. Wang J. Glucose biosensors: 40 years of advances and challenges. Electroanalysis. 2001;13:983-8.

26. Chen Q, Wang Q, Wei G, Liang Q, Qi Q. Production in Escherichia coli of poly(3-hydroxybutyrate-co-3-hydroxyvalerate) with differing monomer compositions from unrelated carbon sources. Appl Environ Microbiol. 2011;77:4886-93.

27. Shang L, Fan CS, Jin RL, Liu DX, Wang JG, Yin J, Song DX. Knockout of tyrR gene in Escherichia coli and its effects on the phenylalanine biosynthesis. Acta Biochim Biophys Sin. 2003;35:728-33.

28. Wang JG, Fan CS, Wu YQ, Jin RL, Liu DX, Shang L, Jiang PH. Regulation of aroP expression by tyrR gene in Escherichia coli. Acta Biochim Biophys Sin. 2003:35:993-7.

29. Livak KJ, Schmittgen TD. Analysis of relative gene expression data using real-time quantitative PCR and the $2(-$ Delta Delta $C(T))$ method. Methods. 2001:25:402-8.

\section{Publisher's Note}

Springer Nature remains neutral with regard to jurisdictional claims in published maps and institutional affiliations.
Ready to submit your research? Choose BMC and benefit from:

- fast, convenient online submission

- thorough peer review by experienced researchers in your field

- rapid publication on acceptance

- support for research data, including large and complex data types

- gold Open Access which fosters wider collaboration and increased citations

- maximum visibility for your research: over $100 \mathrm{M}$ website views per year

At BMC, research is always in progress.

Learn more biomedcentral.com/submissions 